\title{
Glasgow 2004: access presentations online
}

The European Respiratory Society (ERS) has just launched its new web platform for Learning Resources. This new facility gives members centralised access to all the material produced by the ERS, including Congress abstracts, PowerPoint presentations from the ERS Congresses and other events, School Course and Postgraduate (PG) Course material and handouts, web casts and all ERS publications.

Over the last few years, ERS members have expressed a wish to have an easy and integrated way to access the whole host of scientific and educational material produced by the Society. With this in mind, the ERS has developed a new and restructured Learning Resources facility. In addition to all the material that was previously available, the new section will contain 95\% new content. Furthermore, one of the major beneficial features of the new system is the ability to Browse and Search to retrieve information from the enormous range of original material available.

The new Learning Resources facility will allow better dissemination of Congress material. Participants of the Glasgow Congress and those who were unable to attend will be able to retrieve more than 500 original PowerPoint presentations that were prepared specifically for this meeting. Handouts of the Saturday PG Courses will also be available to download in PDF format. Additionally, all of the abstracts from the Glasgow Congress and all Annual Congresses since 1999 can now be searched and retrieved.

In contrast to other medical societies, the ERS wishes to make knowledge and best practice accessible to all respiratory professionals, regardless of their financial resources. Therefore, Learning Resources are freely available to all members. With the new ERS policy on low-income countries making membership more obtainable for more people, access to the most recent and relevant sources of information is becoming possible for respiratory professional everywhere.

For a free tour of the new Learning Resources, visit www.ersnet.org.

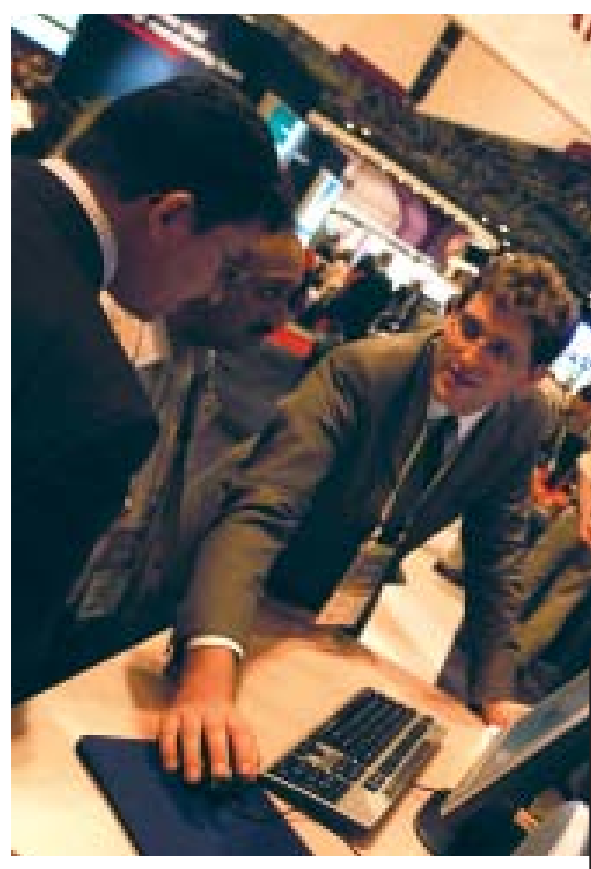

\section{Material available}

From Annual Congresses:

- PowerPoint presentations (currently over 1,000 presentations)

- Abstracts (over 14,000 abstracts)

- Handouts from Postgraduate Courses

- Web casts

- Posters (to come)

\section{From ERS School Courses:}

- PowerPoint presentations

- Handouts

- Web casts

From ERS publications:

- $E R J$ (to come, in connection with Highwire)

- Monograph

- Breathe

- Review

And also:

- Research seminars: PowerPoint presentations and handouts

- Taormina Conferences: PowerPoint presentations, handouts and webcasts

Access to ERS guidelines 